\title{
The feasibility of water vapor sounding of the cloudy boundary layer using a differential absorption radar technique
}

\author{
M. D. Lebsock ${ }^{1}$, K. Suzuki ${ }^{2}$, L. F. Millán ${ }^{1}$, and P. M. Kalmus ${ }^{1}$ \\ ${ }^{1}$ Jet Propulsion Laboratory, California Institute of Technology, Pasadena, California, USA \\ ${ }^{2}$ Department of Earth and Planetary Sciences, University of Tokyo, Tokyo, Japan \\ Correspondence to: M. D. Lebsock (matthew.d.lebsock@jpl.nasa.gov)
}

Received: 30 April 2015 - Published in Atmos. Meas. Tech. Discuss.: 19 June 2015

Revised: 17 August 2015 - Accepted: 26 August 2015 - Published: 8 September 2015

\begin{abstract}
The feasibility of differential absorption radar (DAR) for the spaceborne remote profiling of water vapor within the cloudy boundary layer is assessed by applying a radar instrument simulator to large eddy simulations (LES). Frequencies near the $183 \mathrm{GHz}$ water vapor absorption line attenuate too strongly to penetrate the large vapor concentrations that are ubiquitous in the boundary layer. However it is shown that lower frequencies between 140 and $170 \mathrm{GHz}$ in the water vapor absorption continuum and on the wings of the absorption line, which are attenuated less efficiently than those near the line center, still have sufficient spectral variation of gaseous attenuation to perform sounding. The high resolution LES allow for assessment of the potential uncertainty in the method due to natural variability in thermodynamic and dynamic variables on scales smaller than the instrument field of view. The $(160,170) \mathrm{GHz}$ frequency pair is suggested to best maximize signal for vapor profiling while minimizing noise due to undesired spectral variation in the target extinction properties. Precision in the derived water vapor is quantified as a function of the range resolution and the instrument precision. Assuming an observational spatial scale of $500 \mathrm{~m}$ vertical and $750 \mathrm{~m}$ full width at half maximum (FWHM) horizontal, measurement precision better that $1 \mathrm{~g} \mathrm{~m}^{-3}$ is achievable for stratocumulus scenes and $3 \mathrm{~g} \mathrm{~m}^{-3}$ for cumulus scenes given precision in radar reflectivity of $0.16 \mathrm{dBZ}$. Expected precision in the column water vapor (CWV) is achievable between 0.5 and $2 \mathrm{~kg} \mathrm{~m}^{-2}$ on these same spatial scales. Sampling efficiency is quantified as a function of radar sensitivity. Mean biases in CWV due to natural variability in the target extinction properties do not exceed $0.25 \mathrm{~kg} \mathrm{~m}^{-2}$. Potential biases due to uncertainty in the temperature and pressure profile are negligible rela-
\end{abstract}

tive to those resulting from natural variability. Assuming a $-35 \mathrm{dBZ}$ minimum detectable signal, $40 \%(21.9 \%)$ of stratocumulus(cumulus) atmospheric boundary layer range bins would be sampled. Simulated surface reflectivities are always greater than $-5 \mathrm{dBZ}$, which implies the DAR technique could provide near spatially continuous observation of the CWV in subtropical boundary layers at a spatial resolution better than $1 \mathrm{~km}$.

\section{Introduction}

Existing spaceborne methods for remote sensing of water vapor include passive infrared sounding, passive microwave sounding, passive microwave imaging, near-infrared imaging, and radio occultation approaches. Each of these methods has proven to be exceedingly useful for assimilation in weather models (Andersson et al., 2007) and for climate analysis. Despite their successes, each method has limitations that preclude them from accurately profiling water vapor within the planetary boundary layer. Infrared and microwave sounding methods have water vapor weighting functions that broaden near the Earth's surface limiting the effective information regarding boundary layer water vapor encoded in the observations. Additionally, the boundary layer is frequently populated with clouds, which heavily influence observed infrared spectra. Microwave imagery only provides information on the integrated column water vapor (CWV) and provides no information on how that vapor is distributed within the column. Near-infrared methods do not penetrate the cloudy boundary layer and cannot resolve vertical distributions. Radio occultation is sensitive to boundary layer 
water vapor (Kursinski et al., 1995); however, the utility of the observations is challenged by an additional dependence on the pressure and temperature structure as well as a nonuniqueness in the physics of the inversion problem due to super-refraction of the radio waves (Ao et al., 2003).

The limitations of the current observing systems are unfortunate given that the majority of Earth's water vapor lies within the boundary layer due to the non-linear temperature dependence of the saturation vapor pressure. Because the majority of the water vapor lies within the boundary layer, it is actually the passive microwave imaging sensors that have been shown to provide the most information regarding boundary layer water vapor in advanced assimilation systems (Andersson et al., 2007). However, because these observations lack vertical resolution, the assimilated profile is frequently biased. For example, Kalmus et al. (2015) show that the European Centre for Medium Range Weather Forecasts (ECMWF) model consistently produces a boundary layer that is too shallow and too moist relative to radiosonde data over the subtropical oceans.

The prevalence of recurring boundary layer cloud regimes like stratocumulus and cumulus appear to be associated with subtle variations in the vertical profile of water vapor (Betts and Boers, 1990). Because these different cloud regimes have substantially different cloud radiative effects, the transition from stratocumulus to cumulus is one of the primary uncertainties in estimating the climate sensitivity to anthropogenic radiative forcing. Furthermore, global models frequently produce an unrealistic depiction of the transition from stratocumulus to cumulus and these persistent low cloud biases have far-reaching non-local effects (Gordon et al., 2000; Ma et al., 1996). In situ observations provide a detailed view of the relationship between boundary layer thermodynamic profiles and cloud properties. For example a recent Department of Energy Atmospheric Radiation Measurement (DOE-ARM) field campaign to study the transitions between subtropical cloud regimes and their environment produced 1 year of observations from a container ship traveling back and forth between Honolulu and Los Angeles (Zhou et al., 2015). Figure 1 shows an example from this experiment of the transition of the water vapor profile from one that is well mixed and shallow near the American continent to one that is deep and decoupled near the Hawaiian archipelago. These water vapor profiles are not terribly dissimilar, and yet they are associated with markedly different cloud morphology and thus albedo as shown by the coincident radar reflectivity. One could argue that improvement in the understanding of the response of clouds to climate change may be best facilitated not by improved cloud observations but rather by improved water vapor observations.

High quality in situ observations are useful; however, they are sparse and therefore lack the large-scale context needed for weather model assimilation or climate studies. New observation techniques are needed to fill the gaps of the current observing system. This paper introduces a potential new
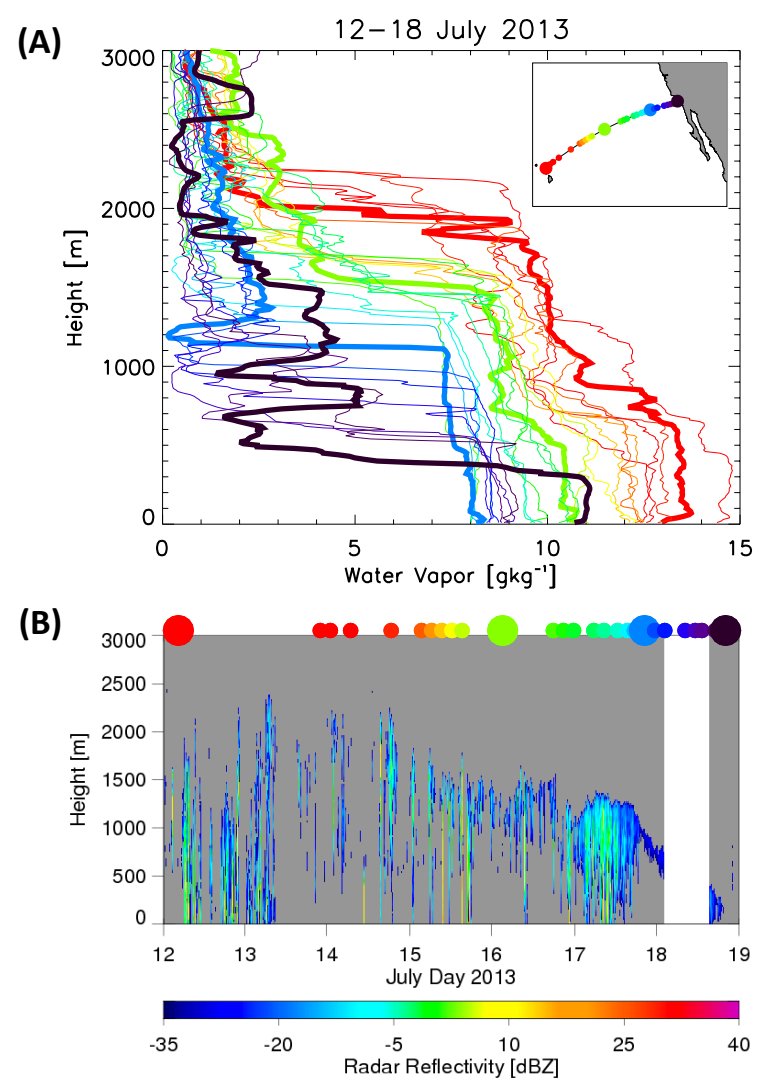

Figure 1. An example of water vapor profiles (a) and the associated cloudiness as shown by the radar reflectivity (b) from one leg of the MAGIC field deployment. MAGIC is the Marine ARM GPCI Investigation of Clouds, GPCI is the GEWEX Pacific Cross-section Intercomparison, and GEWEX is the Global Energy and Water Exchanges. The leg took place between the 12 and 18 July 2013 starting in Hawaii and ending in Los Angeles. The vapor profiles are color coded according to location along the transect, which is shown in the inset map of panel (a). The dots on top of panel (b) correspond to the location of each sounding in panel (a). The white strip in panel (b) is a period where radar data are unavailable. The evolution of the water vapor profile shows a clear transition from one that is well-mixed and shallow to one which grows deeper and more decoupled with distance from the continent. Commensurate with this thermodynamic change is a reduction in cloud cover and an increase in the occurrence of precipitation.

method for boundary layer water vapor sensing using the differential absorption radar (DAR) technique. Prior study of DAR techniques have focused on use of frequencies near the $60 \mathrm{GHz}$ oxygen absorption complex for surface pressure sounding (Flower and Peckham, 1978; Lawrence et al., 2011; Lin and $\mathrm{Hu}, 2005$; Millán et al., 2014). The use of a differential radar signal to retrieve water vapor has previously been explored theoretically using a triplet of frequencies centered on the $22 \mathrm{GHz}$ water vapor absorption line (Meneghini et al., 2005). Observed dual-frequency radar reflectivities using S/Ka band (Ellis and Vivekanandan, 2010) or Ku/W 
band (Tian et al., 2007) have also been used to infer water vapor profiles. With their broad spectral separation these existing dual-frequency methods use observations well off of the water vapor absorption line and into the water vapor continuum. This study shares a common physical theory with all of the above while focusing on water vapor sounding using frequencies in the wings of the $183 \mathrm{GHz}$ absorption line. The theory is general and could be applied to ground or aircraft based instruments; however, the analysis here is specific to a satellite platform.

\section{Differential absorption radar theory}

The theoretical basis for the DAR technique lies in the exploitation of gaseous absorption features that vary strongly with frequency relative to the optical properties of the scattering targets. The technique is analogous to the differential absorption lidar (DIAL) technique (Browell et al., 1979). Specifically, the difference between the radar reflectivity at two frequencies near an absorption line can be related to the amount of absorbing gas between the radar and the scattering target. A descriptive outline of the theory underlying the method is provided here.

Neglecting multiple scattering of the radar beam, the observed (attenuated) radar reflectivity of a pulsed radar system from a cloudy target composed of a distribution of hydrometeors at frequency $(v)$ and range $(r)$ is

$Z(\nu, r)=T(\nu, r) \eta(\nu, r) \frac{\lambda^{4}}{\pi^{5}|K(v, r)|^{2}}$,

where $\lambda$ is the wavelength of radiation, $K$ is the dielectric factor of the target, $T$ is the two-way transmission of radiation along the path, $\eta$ is the volume backscattering coefficient of the target (equal to the integral over the size distribution of hydrometeor backscattering cross sections). When the scattering target is the surface, the radar reflectivity is expressed as

$Z_{0}(v, r)=T(v, r) \frac{\sigma_{0}(v)}{\Phi} \frac{\lambda^{4}}{\pi^{5}|K(v, r)|^{2}}$,

where $\sigma_{0}$ is the normalized surface cross section, and $\Phi$ is the integral of the received waveform shape (Tanelli et al., 2008). Assuming a uniformly filled field of view the two-way transmission is expressed using Beer's law as

$$
\begin{gathered}
T(v, r)=\exp \left(-2 \int_{0}^{r}\left[\sum_{i} \rho_{i, \text { gas }}(r) \kappa_{i, \text { gas }}(\nu, r)\right.\right. \\
\left.\left.+\rho_{i, \text { hydro }}(r) \kappa_{i, \text { hydro }}(v, r)\right] \mathrm{d} r\right)
\end{gathered}
$$

where $\kappa_{\text {gas }}$ is the mass extinction coefficient of the gaseous species, $\kappa_{\text {hydro }}$ is the mass extinction coefficient of the hydrometeor targets integrated over the hydrometeor size distribution, and $\rho$ is the density of the gaseous or condensed species. In these equations range dependence derives from two sources. One source is the pressure and temperature dependence of the absorption line broadening that influences the mass extinction coefficient of the gasses. Another source is the variation in range of the hydrometeor physical and thus optical properties.

If simultaneous observations are made at two frequencies then the ratio of the two radar reflectivities may be expressed as

$$
\begin{aligned}
& \frac{Z\left(v_{1}, r\right)}{Z\left(v_{2}, r\right)}=\frac{\eta\left(v_{1}, r\right) \lambda_{1}^{4}\left|K\left(v_{2}, r\right)\right|^{2}}{\eta\left(v_{2}, r\right) \lambda_{2}^{4}\left|K\left(v_{1}, r\right)\right|^{2}} \\
& \exp \left(-2 \int_{0}^{r}\left[\sum_{i} \rho_{i, \text { gas }}(r)\left(\kappa_{i, \text { gas }}\left(v_{1}, r\right)-\kappa_{i, \text { gas }}\left(v_{2}, r\right)\right)\right.\right. \\
& \left.\left.+\rho_{i, \text { hydro }}(r)\left(\kappa_{i, \text { hydro }}\left(v_{1}, r\right)-\kappa_{i, \text { hydro }}\left(\nu_{2}, r\right)\right)\right] \mathrm{d} r\right) .
\end{aligned}
$$

Equation (4) is quite general; however, it is useful to make some simplifying assumptions to describe the essence of the DAR technique. We further consider that if these frequencies are near an absorption line, the gas giving rise to that line dominates the absorption by other absorbing species. Also for the moment we assume that the spectral variation in the unattenuated radar reflectivity $\left(\eta \lambda^{4} / \pi^{5} K\right)$ is small relative to the spectral variation $\kappa_{\text {gas }}$. With these approximations, Eq. (4) becomes

$$
\begin{aligned}
& \frac{Z\left(v_{1}, r\right)}{Z\left(v_{2}, r\right)}= \\
& \exp \left(-2 \int_{0}^{r}\left[\rho_{\text {gas }}(r)\left(\kappa_{\text {gas }}\left(v_{1}, r\right)-\kappa_{\text {gas }}\left(v_{2}, r\right)\right)\right] \mathrm{d} r\right) .
\end{aligned}
$$

Here and throughout the text, $\rho_{\text {gas }}$ without the summation implicitly refers to the dominant absorbing gas responsible for the absorption line. Finally, expressing the reflectivity in decibels relative to $Z$ units (dBZ) gives the proportionality,

$$
\Delta Z \equiv \mathrm{dBZ}\left(v_{1}, r\right)-\mathrm{dBZ}\left(\nu_{2}, r\right) \propto u_{\text {gas }}=\int_{0}^{r} \rho_{\text {gas }} \mathrm{d} r
$$

Here it is seen that the difference in reflectivity between the two channels $(\Delta Z)$ expressed in the conventional $\mathrm{dBZ}$ units is proportional to the integrated gas path $\left(u_{\text {gas }}\right)$ between the radar and the scattering target. In the case of the surface reflectivity, this quantity is denoted $\Delta Z_{0}$ and $u_{\text {gas }}$ is the column integrated gas path. In the case of water vapor we refer to the gas path as $u_{\text {vapor }}$ or the CWV for the column integral.

The technique may generally be used to obtain an estimate of the CWV because the Earth's surface always provides a backscattering target. A range-gated radar may be used to also provide a profile of water vapor concentration within cloudy targets, where they exist. The profile would be obtained by differencing the derived water vapor path $\left(u_{\text {vapor }}\right)$ 
between adjacent range gates and dividing by the distance between those observed targets. At a minimum this difference would be the radar range resolution; however, it may in principle be any distance larger than this resolution. We note that the differencing of adjacent range gates eliminates much of the uncertainty associated with broadening of the absorption line because the pressure and temperature generally varies in a small and predictable manner between adjacent gates.

To arrive at Eq. (6) it was assumed that the scattering target optical properties are spectrally invariant over a small frequency range and that the contribution to gaseous absorption by other species is negligible near an absorbing line caused by the gas of interest. In practice, the strictness of these assumptions is not necessary, and Eq. (4) remains valid. For example the spectral variation in optical properties can be estimated via a reasonable assumption of the hydrometeor size distribution, and it is only the variability about the assumed spectral slope that is a true source of uncertainty. Similarly, the concentration (and absorption) due to minor absorbing species can be estimated given some a priori information regarding their concentration. Additional complications in the derivation of Eq. (6) include the neglect of multiple scattering and the influence of small-scale heterogeneity within the radar field of view, which is commonly referred to as non-uniform beam filling (NUBF). For the shallow boundary layer clouds considered in this work multiple scattering is generally small. In contrast, NUBF effects may be significant relative to the expected signal.

\section{Models}

\subsection{Cloud model simulations}

A large eddy simulation (LES) model (Matheou and Chung, 2014) is coupled to a 30-bin microphysical model (Suzuki et al., 2010) and used to produce two simulations of the cloudy boundary layer. The bin microphysical scheme is useful in realistically simulating the natural variability in the radar reflectivity, which has a strong dependence on hydrometeor drop size. The first case simulated is the Rain In Cumulus over the Ocean (RICO) (Rauber et al., 2007) using the composite atmospheric conditions outlined in vanZanten et al. (2011). The second simulated case is the Second Dynamics and Chemistry of Marine Stratocumulus field study (DYCOMS-II) (Stevens et al., 2003) using the atmospheric conditions described in Stevens et al. (2005) for Research Flight 01 (RF01). The parameters describing the model setup for each simulation are described in Table 1.

Figures 2 and 3 describe the cloud morphology and boundary layer thermodynamic structure at the specific time steps analyzed in this work. These two cases were chosen to provide two distinct examples of boundary layer cloud regimes where both the cloud and thermodynamic structure resemble the observations of the cloud regime transition shown
Table 1. Conditions for the LES simulations.

\begin{tabular}{lll}
\hline & RICO & DYCOMS-II RF01 \\
\hline Integration time $[\mathrm{hr}]$ & 20.5 & 8.0 \\
Resolution $\left[\mathrm{m}^{3}\right]$ & $40 \times 40 \times 40$ & $10 \times 10 \times 5$ \\
Domain size $\left[\mathrm{m}^{3}\right]$ & $20480 \times 20480 \times 4000$ & $2560 \times 2560 \times 1200$ \\
Initialization Conditions & vanZanten et al. $(2011)$ & Stevens et al. (2005) \\
\hline
\end{tabular}

in Fig. 1. The RICO simulation produces scattered shallow cumulus, some of which produce showers, whereas the DYCOMS-II RF01 simulation produces a shallow and thin stratocumulus cloud layer with near uniform cloud cover. The boundary layer structure is also notably different in the two simulations. The RICO simulation has a deep decoupled boundary layer whereas the DYCOMS-II RF01 boundary layer is shallow and relatively well mixed. In general, the RICO simulation demonstrates greater variability than the DYCOMS-II RF01 simulation. In particular, the significant difference of the in-cloud vapor profiles from the mean profile in RICO is noteworthy.

\subsection{Radar model}

- Water dielectric constant - The dielectric constants of liquid water are calculated using the parameterization described in Ray (1972). A salinity dependence is added following Klein and Swift (1977) for calculations of the sea surface optical constants.

- Hydrometeor properties - The scattering and extinction properties of the hydrometeors at each model grid point are calculated from integration over the prognostic 30-bin drop size distribution (DSD) assuming spherical drops using Mie scattering theory (Bohren and Huffman, 1983).

- Gaseous properties - Gaseous absorption is treated using a variant of the Rosenkranz (1998) model which is a modification of the (Liebe et al., 1993) Millimeter-wave Propagation Model (MPM).

- Radiation Propagation - Radar reflectivity is modeled using the time-dependent two-stream (TDTS) model (Hogan and Battaglia, 2008). This model includes the single scattering contribution to the reflectivity given by Equation 1 as well as a two-stream approximation for the multiply scattered photons. However, the multiply scattered contribution is generally very small in the simulations examined here. Because this is a onedimensional model, NUBF was accounted for in postprocessing as described in the next section.

- Surface reflection - The normalized surface cross section $\left(\sigma_{0}\right)$ is calculated using the model of Li et al. (2005) with the Freilich and Vanhoff (2003) formulation for the wind speed dependence of mean square slope of the surface. This model is a semi-empirical fit to observations 
(A)

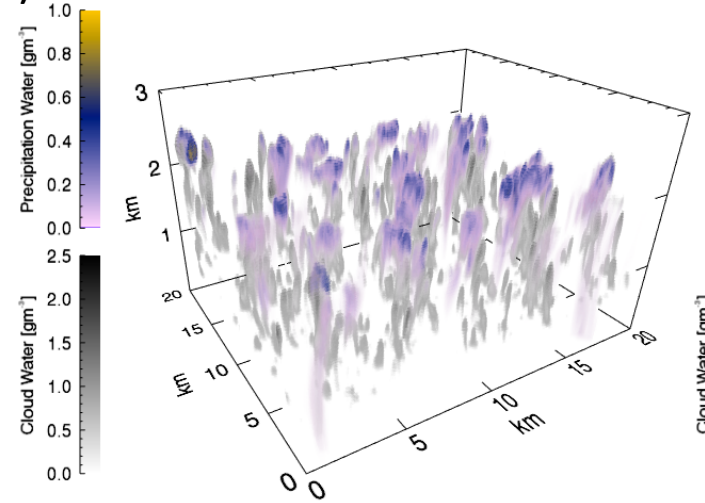

(B)

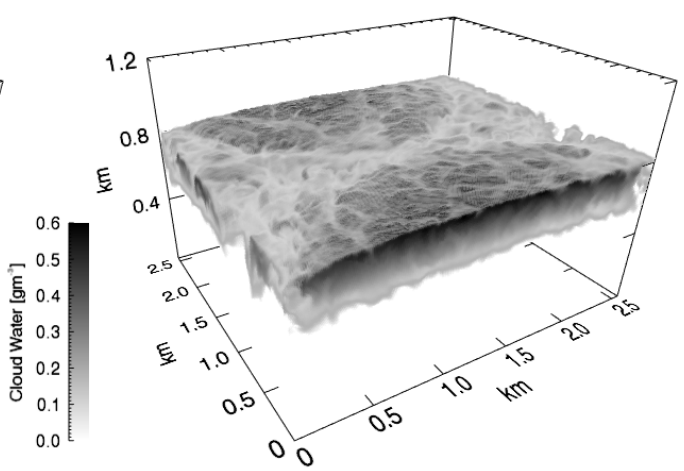

Figure 2. Three-dimensional rendering of the LES time steps analyzed in this work for RICO (a) and DYCOMS-II RFO1 (b). Gray scale shows cloud water content, while color scale shows precipitation water. No precipitation is present in the DYCOMS simulation.
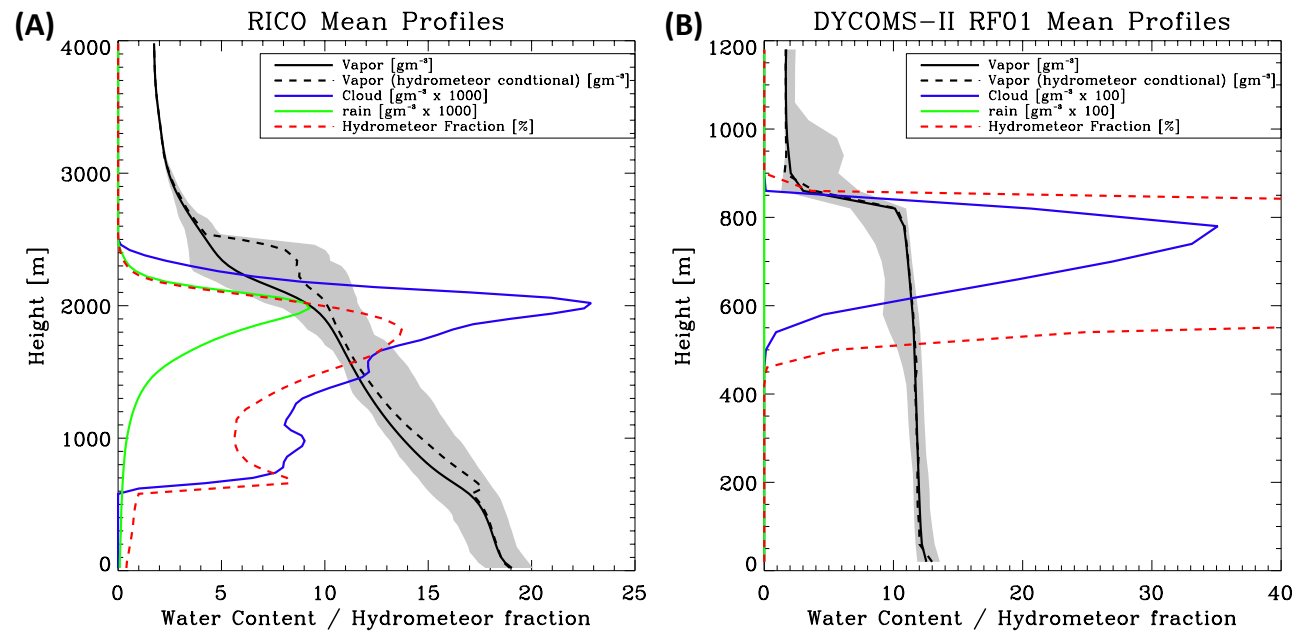

Figure 3. Mean profiles for the RICO (a) and DYCOMS-II RF01 (b) simulations. The solid black line shows the mean vapor profile, the dashed black line shows the "in-cloud" conditional mean vapor profile, and the gray shading shows the range of the water vapor density. Cloud and rain water are shown in blue and green respectively. The dashed red line shows the fraction of atmosphere filled with hydrometeors at each height.

at $94 \mathrm{GHz}$ and includes a correction factor $\left(C_{\mathrm{e}}=0.88\right)$ to the Fresnel reflection coefficient due to the diffraction effects of waves small in scale relative to the wavelength of radiation. This work examines wavelengths roughly half that observed in Li et al. (2005); therefore, $C_{\mathrm{e}}$ should be closer to unity. Given the lack of observational constraint at the frequencies considered $C_{\mathrm{e}}$ is set to one in these simulations. Salinity is set to a constant $35 \%$ o for calculation of the dielectric constant.

\subsection{Applying the radar model to the cloud simulations}

In this work one time step is analyzed from the last $10 \%$ of the LES integration to avoid the model spin-up period prior to the model reaching a dynamically steady state. Profiles of thermodynamic variables were acquired from ancillary sources and added to the top of the LES domain to model attenuation by gasses above the LES boundary (shown in Fig. 3) and have a better representation of a spaceborne measurement system. For the RICO simulation, composite radiosonde observations launched from the research vessel Seward Johnson during the field campaign are used. For the DYCOMS-II RF01 simulation, composite profiles are created from the ECMWF interim reanalysis (Dee et al., 2011). Minor scaling was required to avoid discontinuities in the thermodynamic profiles at the model boundary. We note that although the effect of adding gaseous attenuation above the boundary layer on the modeled reflectivities is non-negligible, it is minor relative to the gaseous attenuation within the boundary layer. For both LES the added attenuation varies between approximately 1 and $5 \mathrm{~dB}$ between 140 and $170 \mathrm{GHz}$. 
The radar model is applied to each column of the cloud simulations at the LES native resolution with a nadir view angle. The modeled reflectivities are then convolved with an idealized Gaussian antenna gain pattern with a $3 \mathrm{~dB}$ beam width of $750 \mathrm{~m}$ and a top-hat range resolution of $240 \mathrm{~m}$ to capture the effects of NUBF and variability in range at subresolution scales. This notional resolution is representative of current spaceborne radar capabilities and concepts. Off-nadir view angles that would be provided by scanning radar are not explored here but are in principle not fundamentally different than a nadir viewing geometry.

Frequencies between 140 and $170 \mathrm{GHz}$ are simulated in $5 \mathrm{GHz}$ increments along with $94 \mathrm{GHz}$, the frequency of CloudSat, which is shown for reference. Frequencies higher than $170 \mathrm{GHz}$ nearer to the absorption line center would provide better differential signal than this lower frequency region stretching from the wings of the absorption line into the water vapor absorption continuum. However, they tend to be so strongly attenuated by water vapor that they would not be able to penetrate the large vapor burden of the marine boundary layer.

A central element of this modeling framework is that the high spatial resolution of the LES and bin representation for microphysics allows us to explore the influence of spatial variability in the meteorology and in microphysics that would impact an observation but are not included in the descriptive representation of the DAR concept given in Eq. (6). For example, the spatial variability in the thermodynamics, near-surface wind speed, cloud organization and microphysics influence the simulated radar reflectivity and therefore distort the relationship one would expect between $\Delta Z$ and $u_{\text {vapor }}$ at the LES native resolution. The LES model test bed serves as an ideal tool for examining these NUBF effects introduced by the sub-field-of-view variability. Microphysical variability also influences the modeled radar reflectivities. This variability can only be realistically modeled with a bin microphysical representation of the drop size distribution. The noise introduced by this variability is implicitly modeled in these simulations because the variations in the drop size distribution introduce variability in the spectral dependence of hydrometeor optical properties. Radar simulations using the full 30-bin microphysics are significantly different than those using a two-moment representation of the size distribution. This is particularly true for the RICO case where the single moment calculations are biased $-2.1 \mathrm{dBZ}$ from the bin calculations with a root mean square difference of $7.4 \mathrm{dBZ}$.

\section{Results}

\subsection{Example signal}

The focus of this paper is on the feasibility of water vapor sounding of the planetary boundary layer using a DAR

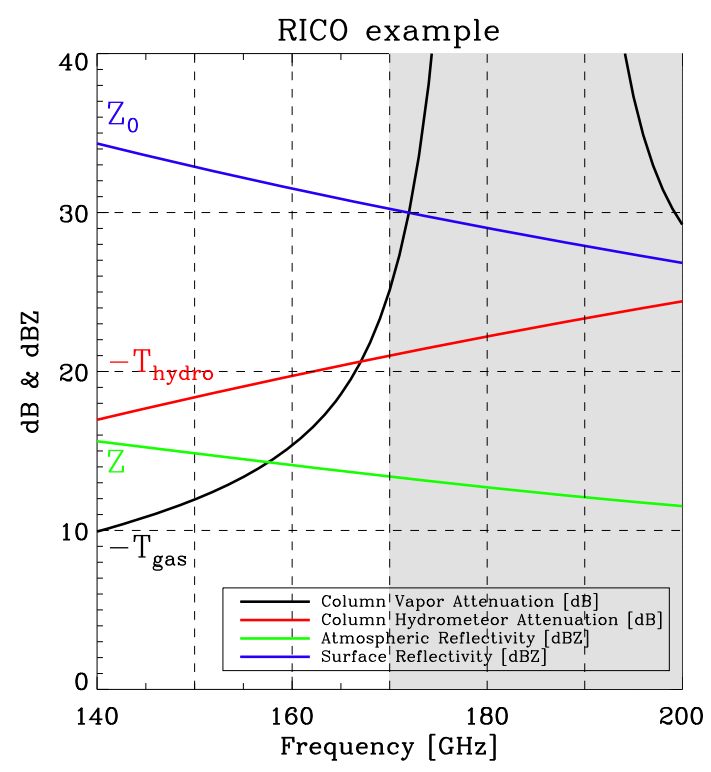

Figure 4. An example of the spectral variation of the column twoway attenuation due to water vapor, the two-way attenuation due to hydrometeors, the surface reflectivity assuming a range resolution of $240 \mathrm{~m}$, and the hydrometeor reflectivity. This example is from a single precipitating column in the RICO simulation. The gray shaded frequencies are not examined in this work because of the large attenuation due to vapor near the absorption line.

technique from a spaceborne platform. To this end we first demonstrate the spectral variation of the extinction and scattering across the frequency range between 140 and $170 \mathrm{GHz}$. This spectral range is chosen because of our focus on a likely power-limited satellite platform, which would require the avoidance of heavily attenuating frequencies near the water vapor absorption line. The closer the frequencies are to the absorbing line the greater the signal-to-noise would be and we note that application of the technique from an aircraft or ground-based platform may find the higher frequency channels useful. It is further noted that sounding of higher altitudes in the middle and upper troposphere would not only benefit from but also necessitate higher (more strongly attenuating) frequencies at which the $\Delta Z$ signal increases substantially.

Figure 4 shows an example from a single precipitating column in the RICO simulation. The column water vapor attenuation varies by $15 \mathrm{~dB}$ across the frequency interval whereas the hydrometeor and surface scattering all vary by less than $4 \mathrm{~dB}(\mathrm{dBZ})$. The characterization of the spectral variation of the other variables would be a source of uncertainty in any retrieval algorithm for the water vapor. Here it is made clear why we do not explore frequencies higher than $170 \mathrm{GHz}$ because of the large values of attenuation near the water vapor line exceeding $40 \mathrm{~dB}$. The sensitivity of water vapor to frequency is much greater at the higher frequencies near $170 \mathrm{GHz}$ in the wings of the absorption line than at the lower 
(A)
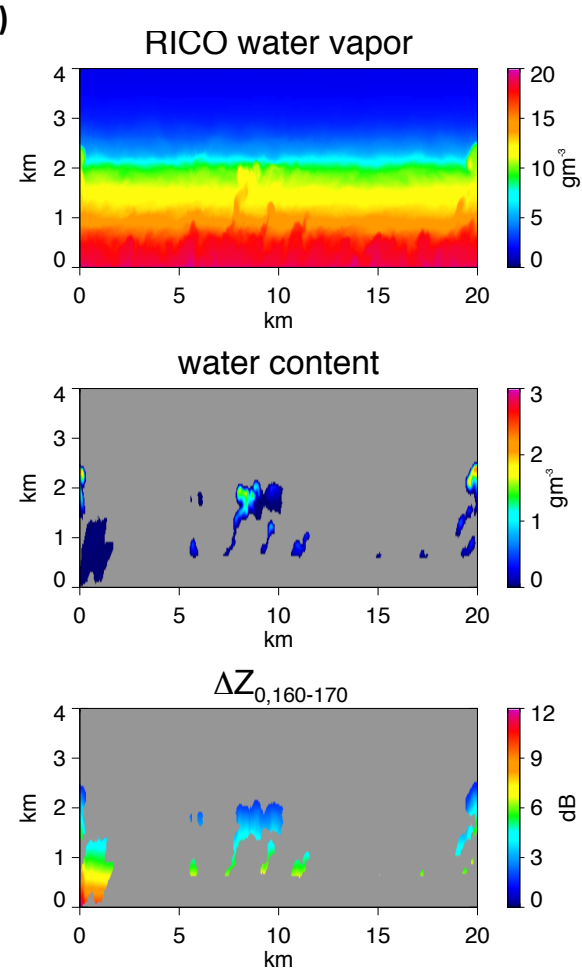

(B)
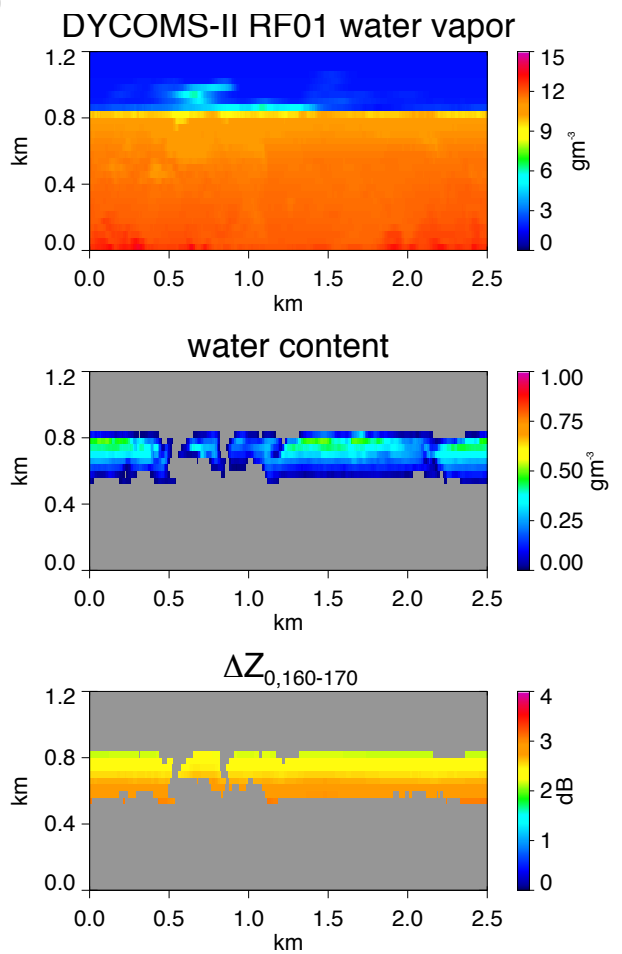

Figure 5. Cross sections of water vapor, total liquid water content and the reflectivity difference between 160 and $170 \mathrm{GHz}$ for RICO (a) and DYCOMS-II RF01 (b).

continuum absorption frequencies where the sensitivity of the water vapor attenuation to frequency is the same order of magnitude as the sensitivity of the other variables. For example, between 160 and $170 \mathrm{GHz}$, the water vapor sensitivity is approximately $10 \mathrm{~dB}$, whereas the sensitivity of the other parameters are one to two $\mathrm{dB}(\mathrm{dBZ})$. This result shows that the assumptions outlined in Section 2 that the spectral variation of the water vapor is significantly larger than that of the target backscattering is moderately satisfied in the $183 \mathrm{GHz}$ line wings but not in the continuum absorption region. As a consequence, line pairs near $140 \mathrm{GHz}$ (i.e. 140/145) would not likely have an exploitable signal-to-noise ratio whereas line pairs near $170 \mathrm{GHz}$ (i.e. $165 / 170$ ) would be potentially exploitable for vapor sounding.

\subsection{Example Profiles}

Figure 5 shows cross sections of the water vapor, water content, and $\Delta Z_{160-170}$ for RICO and DYCOMS-II RF01. Figure 6 shows specific simulated profiles of radar reflectivity and $\Delta Z$ after convolution with the antenna gain pattern for three different pixels. One profile from the DYCOMSII RF01 simulation is shown in Fig. 6 along with a raining and a non-raining profile from the RICO simulation. The $94 \mathrm{GHz}$ reflectivity is also shown in Fig. 6 for reference. Several important points can be drawn from these examples. First, the reflectivity differences increase with depth into the cloud layer as the radar beams traverse increasing water vapor path. Even for the smallest frequency difference considered $(165-170 \mathrm{GHz})$ the simulated reflectivity differences are always greater than $1 \mathrm{dBZ}$, even at the top of the cloud layer. These $\Delta Z$ values are much larger than the precision of already proven spaceborne radars. Second, note the significant attenuation relative the $94 \mathrm{GHz}$ reference experienced at all of the frequencies between 140 and $170 \mathrm{GHz}$. The effect of this attenuation is particularly evident in the RICO simulation compared to the DYCOMS-II RF01 simulation because of the differences in moisture between the two simulations. Despite the attenuation, even at $170 \mathrm{GHz}$ these examples show reflectivities that would be observable with a sensitivity of $-30 \mathrm{dBZ}$, which is comparable to the sensitivities of $-28 \mathrm{dBZ}$ for CloudSat (Tanelli et al., 2008) and $-35 \mathrm{dBZ}$ for EarthCare (Takahashi et al., 2009). These sensitivities are approximately comparable to those achievable at higher frequencies because radar output power decreases with frequencies while antenna gain increases for a fixed diameter. Third, the surface equivalent reflectivity is greater than $-5 \mathrm{dBZ}$ at all frequencies for all simulated observations. This is a readily achievable minimum detectable signal that would permit spatial continuous estimation of the CWV at a very high resolution relative to existing observation methods. Fourth, note that because the cloud layer is thin and shallow in the DYCOMS-II RF01 case, there are at most 
(A)
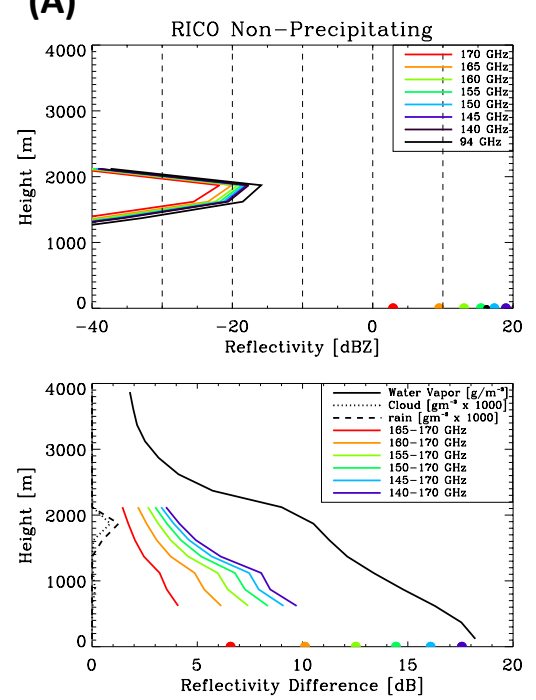

(B)
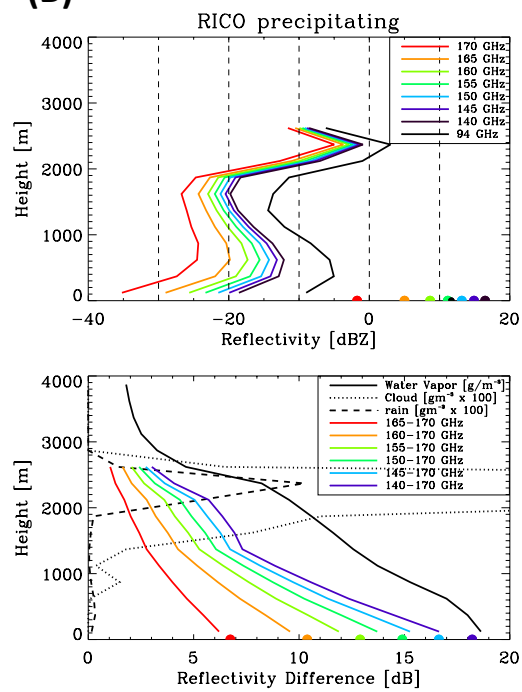

(C)
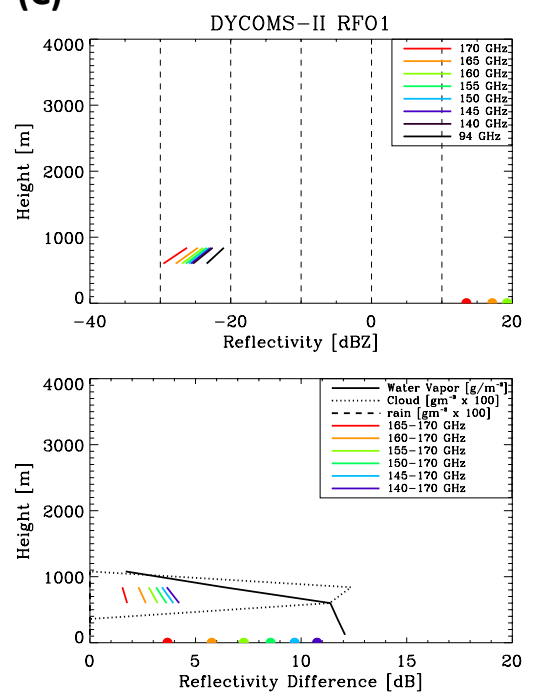

Figure 6. Reflectivity profiles (top) and reflectivity difference (bottom) for a non-precipitating RICO pixel (a), a precipitating RICO pixel (b), and a DYCOMS pixel (c). These examples have been averaged to the antenna gain function and range resolution. The dots at the height $=0$ level show the surface reflectivity. In the bottom panels the water vapor profile and cloud and precipitation profiles are also shown.

three pieces of information available, two atmospheric reflectivities and a surface reflection. In contrast, because precipitation reaches the surface in the RICO case reflectivities are available throughout the lowest $3 \mathrm{~km}$ of the atmosphere. Fifth, notice in Fig. 5 that the variability in the water vapor distribution in RICO is positively correlated with cloud elements. DAR retrievals of water vapor, which depend on cloudy reflectivities, would therefore be subject to a conditional sampling high-bias in scattered cumulus conditions. In contrast, this effect is negligible in the DYCOMS simulation where cloud cover is relatively homogenous. Finally, as the frequency separation between channel pairs grows the signal increases at an asymptotic rate because the further the frequency is from the $183 \mathrm{GHz}$ absorption line the smaller the rate of change of extinction with frequency becomes.

\subsection{Relationship between vapor path and reflectivity difference}

The previous section showed a few examples of the DAR signal for water vapor. We now examine the water vapor signal using all simulated pixels and range bins. The theory leading to Eq. (6) predicts a linear relationship between water vapor path and reflectivity difference. The linearity is confirmed in Fig. 7, which shows the relationship between the $u_{\text {vapor }}$ and $\Delta Z$ for all simulated range bins including the surface. However it is also apparent that substantial scatter can distort the signal, particularly as the frequency separation increases (i.e. $140-170 \mathrm{GHz}$ ). The slope of the plots may be interpreted as a signal for water vapor, and the scatter about those lines may be interpreted as noise. Note that the scatter is much larger in the RICO simulation than in the DYCOMS-II RF01 simula- tion. This is due to the presence of precipitation and greater spatial variance resulting in greater spectral variation in the extinction properties of the targets. Notice that this scatter exists not only in the atmospheric $\Delta Z$ 's but also to a lesser extent in the surface $\Delta Z_{0}$ 's. Some variability in the spectral dependence of $\sigma_{0}$ results from variations in the near-surface wind speed; however, most of the scatter in $\Delta Z_{0}$ derives from spectral variation in the column attenuation. Importantly this indicates that the spectral variation of the attenuation within the column between the radar and the target may be as important as the spectral variation of the backscattering target in contributing to noise in the water vapor signal.

The surface reflectivity difference provides information regarding the column water vapor. Figure 8 shows the relationship of $\Delta Z_{0}$ for the $(160 / 170) \mathrm{GHz}$ frequency pair and the CWV. Observe that in clear-sky pixels a robust linear relationship exists between the CWV and $\Delta Z_{0}$. The presence of hydrometeors distorts this linearity and the effects of precipitation, which are present in RICO, contribute substantially to NUBF. The NUBF effects are present in both simulations but are significant larger in the RICO case. The behavior of the NUBF effects in the RICO simulation is worth description. At the native spatial resolution, the spectral variation in hydrometeor extinction properties causes an increase in $\Delta Z_{0}$ relative to that which would be predicted by water vapor alone. This $\Delta Z_{0}$ increase is particularly evident in the presence of precipitation. This behavior is caused because the sensitivity to frequency of attenuation from both vapor and hydrometeors is of the same sign (e.g. Fig. 4). In contrast, convolution of the signal with the antenna gain pattern to simulate NUBF results in a decrease in $\Delta Z_{0}$ relative to 
(A)

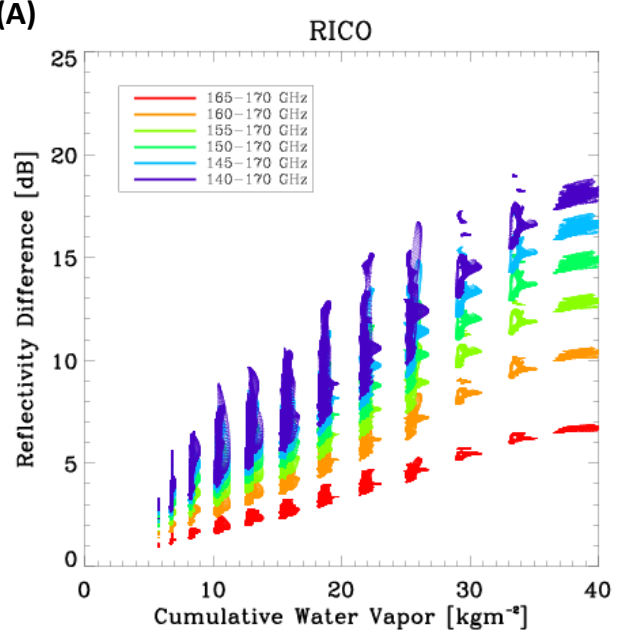

(B)

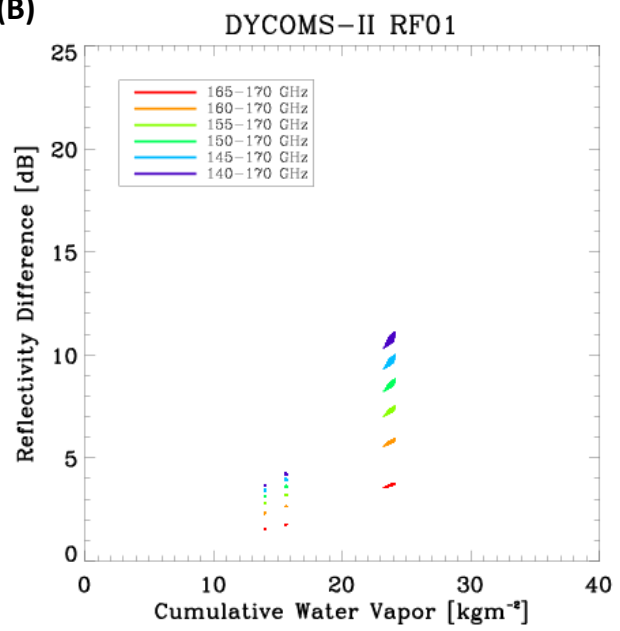

Figure 7. A scatter plot of the water vapor path $\left(u_{\mathrm{vapor}}\right)$ between the radar and the target range gate and the reflectivity difference. RICO is shown in (a) and DYCOMS-II RF01 is shown in (b). These points have been convolved with the antenna function and range resolution. The slope of the relationship is interpreted as a signal, and the scatter about that slope is the noise due to natural variability. Notice that the scatter is much larger in the RICO simulation than in the DYCOMS-II RF01 simulation. Signal increases with frequency separation; however, the noise does as well. The clusters of points with the largest vapor paths correspond to the surface reflectivity.

the expected water vapor contribution. The decrease occurs because the ratio of the reflectivities is a nonlinear negative exponential function of the water vapor path (Eq. 5). Spatial averaging of the reflectivity therefore maps into an underestimate of the water vapor path via Jensen's inequality. In effect, the precipitation influence and the NUBF influence compete against each other and tend to cancel one another out. Both effects tend to have larger magnitudes in the presence of precipitation. Because the DYCOMS simulation produces much more homogenous cloud the NUBF is much less affected by this non-linear averaging effect and both the native and smoothed resolution reflectivity differences are biased slightly high.

\subsection{Uncertainty analysis}

\subsubsection{NUBF and microphysical variability effects on precision}

It is clear that a signal exists for boundary layer water vapor in the wings of the $183 \mathrm{GHz}$ water vapor line and extending into the continuum absorption spectral range between 140 and $170 \mathrm{GHz}$. To this point it has not been demonstrated whether this signal is sufficiently large relative to measurement noise to retrieve water vapor within reasonable uncertainty bounds. We now examine what precision might be achieved for various frequency pairs.

Expected retrieval precision for the total CWV is given by

$\delta_{\text {vapor,path }}=\frac{\sqrt{2 \delta_{\text {meas }}^{2}+\delta_{\text {surf }}^{2}}}{S}$, with units of mass per unit area. The precision for the volumetric vapor content is

$\delta_{\text {vapor, volume }}=\frac{\sqrt{4 \delta_{\text {meas }}^{2}+\delta_{\mathrm{atm}}^{2}}}{S \Delta h}$,

with units of mass per unit volume. Here $S$ is approximated as the sensitivity of the radiative transfer to variation in the column water vapor in cloud free pixels $(S=$ $\left.\partial \Delta Z_{0} / \partial \mathrm{CWV}\right), \Delta h$ is the desired vertical resolution, and $\delta_{\text {meas }}$ is the instrument precision. It is emphasized that $S$ is not the radar sensitivity; rather it is the sensitivity of the radar forward model to the vapor path. Complicating this calculation is the natural variability in the $u_{\text {vapor }}-\Delta Z$ relationship caused by NUBF or spectral variation in the hydrometeor extinction properties and surface backscatter. This natural variability noise is given by $\delta_{\text {atm }}$ and $\delta_{\text {surf }}$, and it is added in quadrature with the uncorrelated instrument precision. There are three differences between the volumetric and path uncertainties. The first is the $\Delta h$ term signifying the desired range resolution. This may be equal to or integer multiples of the instrument resolution. Intuitively, as the desired vertical resolution decreases, there is a commensurate decrease in the retrieval uncertainty. Second, making a volumetric quantification of the water vapor content involves four reflectivity measurements, whereas making a path quantification involves only two observations. As a result volumetric retrievals suffer a doubling of the variance due to instrument precision. Third, the natural variability of the target is the surface for the path estimation, whereas it is the clouds and precipitation for the volumetric estimation. Natural variabil- 
(A)

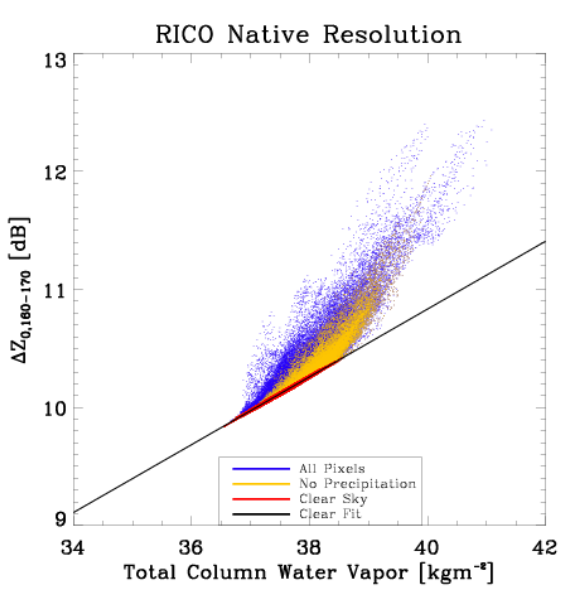

(C)

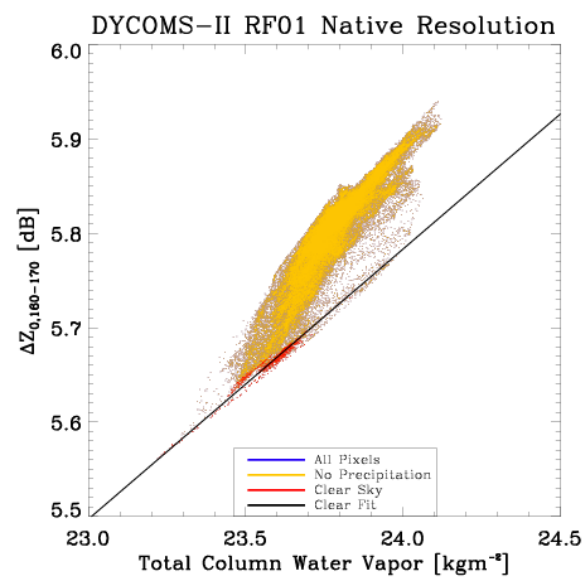

(B)

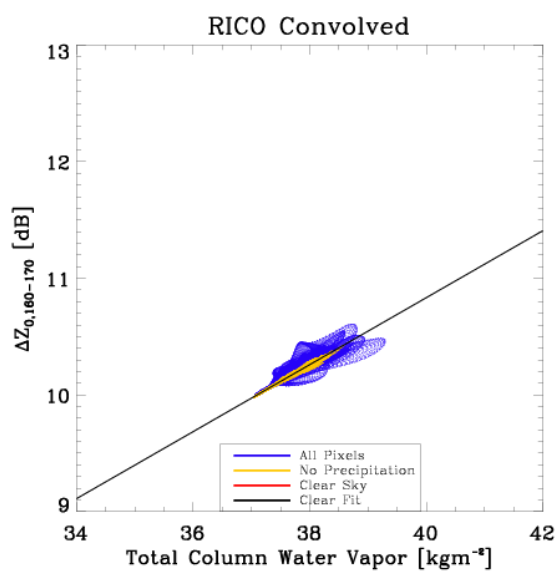

(D)

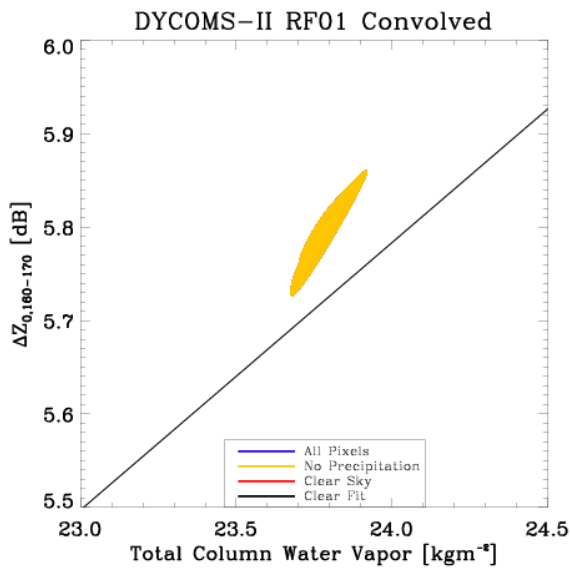

Figure 8. Scatter of the CWV against the reflectivity difference for the $(160,170) \mathrm{GHz}$ channel pair for each simulation. Both the native resolution and the resolution averaged to the antenna gain function are shown. Non-precipitating columns and cloud-free pixels are distinguished from precipitating columns. The black line shows a linear fit of the native resolution $\Delta Z$ to the CWV for cloud free columns. Note that the RICO and DYCOMS-II RF01 plots have different scales.

ity in the surface reflectivity tends to be smaller than that of atmospheric targets (i.e. Fig. 7).

In reality, the precision will vary slightly from point to point based on subtle variation in the sensitivity and larger variation in the natural variability in $\Delta Z$. This spatial variability in precision, while interesting, is ignored in the analysis here to provide a more general depiction of the expected uncertainty characteristics. The sensitivity is approximated as the slope of a linear fit between the CWV content and $\Delta Z_{0}$. This approximation ignores modest temperature and pressure dependent variation of the absorption. The noise due to the natural variability is more difficult to approximate. As a first order approximation, the noise is calculated as the mean of the standard deviations of $\Delta Z$ at each range bin vertical level. This may be considered a conservative overestimate of this source of noise because it assumes that only the simplest native retrieval is possible. In reality, a retrieval algorithm could make a reasonable estimate of the spectral dependence of the hydrometeor extinction properties, $\Delta Z$ would be correlated from level to level within a given pixel, and NUBF corrections could be applied.

Ignored in this analysis are errors in the radar forward model including the TDTS and spectroscopy errors. In these largely single scattering environments uncertainty in the TDTS solution will be small. However spectroscopy errors may be substantial, and any pursuit of DAR for water vapor sounding would require a dedicated characterization of the relevant spectroscopy and associated uncertainties.

Figure 9 shows the expected retrieval precision for the total CWV as a function of instrument precision for a number of frequency pairs. The estimated retrieval precision always increases with spectral separation. The uncertainty estimates are approximately 4 times larger for RICO than for DYCOMS-II RF01 because of the larger scatter in the surface cross section that exists in the RICO simulation. Results suggest that retrieval of CWV to within $1 \mathrm{~kg} \mathrm{~m}^{-2}$ is always achievable in DYCOMS-II RF01 and is realistic in RICO given appropriate frequency selection. This is a result of only modest natural variability in the simulated surface 

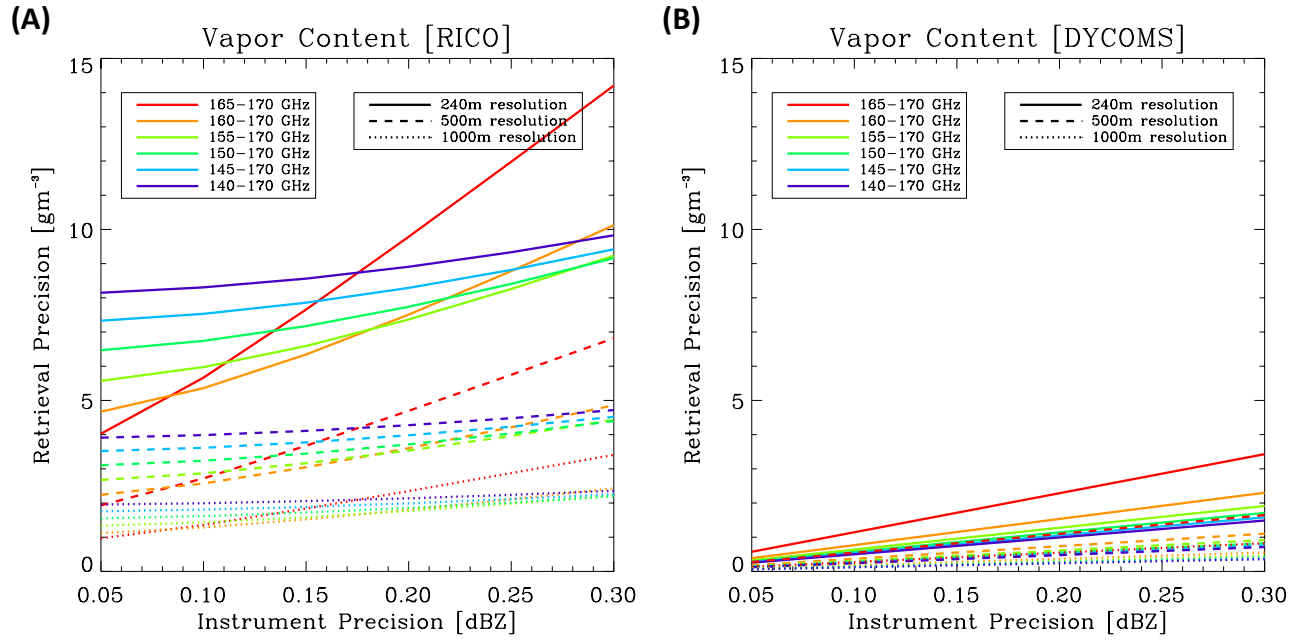

Figure 9. Estimated CWV retrieval precision as a function of instrument measurement precision for RICO (a) and DYCOMS-II RF01 (b).

backscatter, which includes contributions due to small-scale variation in the near-surface wind speed and NUBF effects on the column attenuation. However, it is cautioned that it is likely that the spectral dependence of the surface reflectivity is less well known than is modeled here and any uncertainty in this formulation will be amplified with increased spectral separation.

The expected precision of the volumetric vapor density is shown in Fig. 10. These results are more complex than those for the CWV. Notice first that there are different curves for various vertical retrieval resolutions with precision increasing as resolution decreases. Large differences are seen between the DYCOMS-II RF01 and the RICO simulations. Uncertainties for RICO are much larger than those for DYCOMS-II RF01, particularly when the instrument precision is high and the noise in $\Delta Z$ is dominated by the natural variability. This is a reflection of the much greater variability in the RICO simulation relative to DYCOMS-II RF01. For DYCOMS-II RF01, where scatter in the $u_{\text {vapor }}-\Delta Z$ relationship is low increased spectral separation always increases retrieval precision. This is not true for RICO where neither the $(140,170) \mathrm{GHz}$ frequency pair or the $(165,170) \mathrm{GHz}$ frequency pair is optimal. Instead there is a gradual trend from low variability pairs performing well when instrument precision is high and high variability pairs performing well when instrument precision is low. For a $0.16 \mathrm{dBZ}$ precision (the precision of CloudSat), the $(160,170) \mathrm{GHZ}$ pair performs best with retrieval precision better than $3 \mathrm{~g} \mathrm{~m}^{-3}$ for RICO and $1 \mathrm{~g} \mathrm{~m}^{-3}$ for DYCOMS-II RF01, assuming a desired resolution of $500 \mathrm{~m}$.

Consider that these precisions could be achieved at a spatial resolution less than $1 \mathrm{~km}$. Averaging over larger areas this uncertainty would be reduced by a factor of $1 / \sqrt{n}$. Even with nadir only sampling this would be approximately a factor of 5 reduction over a $20 \mathrm{~km}$ area assuming continuous sampling (cloud cover). As a point of reference, uncertainty in the CWV derived from modern passive microwave imagers such as the Advanced Microwave Scanning Radiometer for EOS (AMSR-E) series has a $3 \mathrm{~dB}$ spatial resolution of $29 \times 17 \mathrm{~km}^{2}$ and an estimated precision of $0.57 \mathrm{~kg} \mathrm{~m}^{-2}$ (Wentz and Meissner, 2000). Compare this with the potential for better than $1 \mathrm{~kg} \mathrm{~m}^{-2}$ precision at a spatial scale less than $1 \mathrm{~km}$ from a DAR system.

\subsubsection{NUBF and microphysical variability effects on CWV bias}

The scatter observed in the relationship between CWV and $\Delta Z_{0}$ would result in errors in the potential retrieval of CWV. Here we document this bias using the data presented in Fig. 8. Table 2 shows the statistics of the error in a hypothetical CWV retrieval due to the presence of condensed hydrometeors by differencing the actual CWV from one that is predicted based on a linear least squares fit between $\mathrm{CWV}$ and $\Delta Z_{0}$ for cloud free pixels at the LES native resolution. These linear fits are also drawn in Fig. 8. First notice in Panels $\mathrm{A}$ and $\mathrm{C}$, which show the results at the native LES resolution, that the effect of condensed water is to result in a positive bias in the CWV that would be inferred from $\Delta Z_{0}$. Interestingly NUBF is seen to have either neutral (DYCOMSII RF01) or positive (RICO) influence on the potential errors (Panels $\mathrm{B} / \mathrm{D})$. The mean bias error for $\mathrm{CWV}$ is lower in the RICO case than it is in the DYCOMS case. This is because there are many clear and nearly clear-sky pixels in the RICO simulation where the hydrometeors do not influence the signal. Despite this fact, RICO has the largest individual pixel errors due to the greater spatial variability and the presence of precipitation. Considering both cloudy and clear pixels with the assumed antenna function and range resolution, the maximum RICO biases approach $1 \mathrm{~kg} \mathrm{~m}^{-2}$, whereas they are roughly half as large in the DYCOMS case. However the 

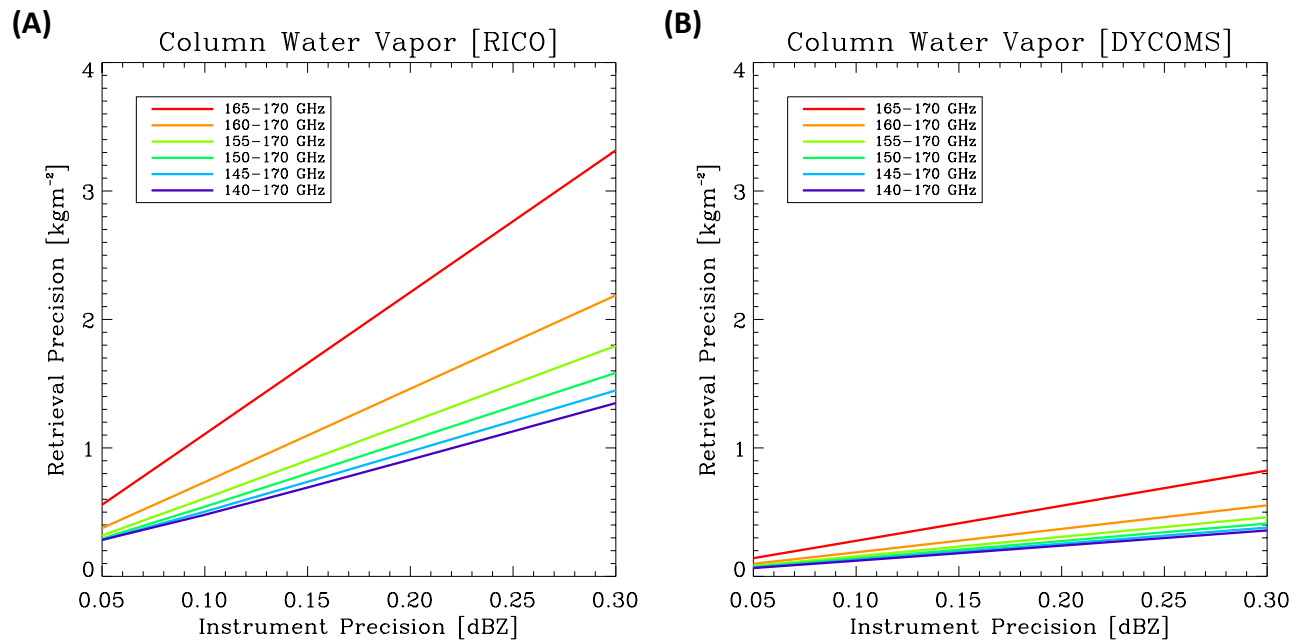

Figure 10. Estimated vapor density retrieval precision as a function of instrument measurement precision for RICO (a) and DYCOMS-II RF01 (b). The solid, dashed, and, dotted lines correspond to different vertical resolutions for the retrieval, which may be lower than that of the reflectivity observations.

bias of the mean is $0.25 \mathrm{~kg} \mathrm{~m}^{-2}$ in DYCOMS-II RF01 and approximately an order of magnitude smaller for RICO.

\subsubsection{Pressure and temperature biases}

Uncertainty in the pressure $(P)$ and temperature $(T)$ will result in an associated uncertainty in the absorption line broadening. We estimate this uncertainty in reflectivity as

$\delta_{T}=\frac{\partial Z}{\partial T} \delta T ; \delta_{P}=\frac{\partial Z}{\partial P} \delta P$.

The partial derivatives are calculated using a $1 \mathrm{~K}$ or $1 \mathrm{hPa}$ perturbation applied to the entire column. Applying the perturbation to the entire column most likely provides an overestimate of uncertainty because it is likely that uncertainty in the thermodynamic parameters becomes uncorrelated with distance, which would result in a cancelation of errors. Therefore the sensitivities that are calculated should be considered an upper bound. A second difficulty in estimating these uncertainties is estimating $\delta T$ and $\delta P$. Here we assume a $2 \mathrm{~K}$ temperature perturbation based on Eyre (1990) and a $5 \mathrm{hPa}$ perturbation in pressure following Salstein et al. (2008), which shows that this perturbation roughly bounds the uncertainty in operational surface pressure analysis.

Table 3 shows the results of the perturbation calculations. The reflectivity bias increases with frequency as one approaches the line wings. At frequencies less than $160 \mathrm{GHz}$ there is little influence from the $183 \mathrm{GHz}$ line and spectrally flat bias is observed. This would be no problem since it is $\Delta Z$ that provides the signal, and the bias would therefore cancel out. However, as we have shown, a channel near $170 \mathrm{GHz}$ is necessary to make the technique feasible. However, even at $170 \mathrm{GHz}$ the largest bias that we estimate is $0.02 \mathrm{dBZ}$, which is well below any reasonable expectation for instrument pre-
Table 2. Statistics of the error for the retrieval of the total column integrated water vapor assuming a naïve linear regression based retrieval.

\begin{tabular}{llrrrr}
\hline & Standard deviation & Bias & Min & Max & \\
\hline Convolved & DYCOMS & 0.060 & 0.253 & 0.121 & 0.355 \\
resolution & RICO & 0.086 & 0.023 & -0.782 & 0.838 \\
& RICO (no precip) & 0.024 & -0.002 & -0.205 & 0.135 \\
\hline Native & DYCOMS & 0.097 & 0.266 & -0.040 & 0.439 \\
resolution & RICO & 0.372 & 0.128 & -0.077 & 5.506 \\
& RICO (no precip) & 0.187 & 0.043 & -0.077 & 3.880 \\
\hline
\end{tabular}

cision or the biases that may be incurred from NUBF and variation in the spectral slope of the target scattering properties (i.e., Table 2).

\subsection{Sampling}

As we have previously mentioned the surface reflectivity of the simulated radar system always exceeds $-5 \mathrm{dBZ}$ in the two LES scenarios examined here. This would be a readily achievable sensitivity threshold relative to existing spaceborne radars. Therefore for the stratocumulus and cumulus environments examined here spatially continuous observations of the CWV could be expected. However, other environments which are either very moist or have heavy precipitation may not permit estimation of CWV.

Atmospheric profiling would only be possible where scattering targets (i.e. clouds) that have reflectivities greater than the radar sensitivity will provide sampling opportunities. Table 4 provides the sampling statistics for sampling the boundary layer for radar sensitivities of -40 through $-10 \mathrm{dBZ}$. Here the boundary layer is defined as the height of the LES domain. The most absorbing $170 \mathrm{GHz}$ channel and the least 
Table 3. Uncertainty in the radar reflectivity due to $2 \mathrm{~K}$ bias in temperature or a $5 \mathrm{hPa}$ bias in pressure. Temperature and pressure biases are applied uniformly throughout the atmospheric column and radar reflectivities are calculated from the perturbed state. The radar reflectivity uncertainties shown in the table are the mean of all pixels in each LES.

\begin{tabular}{lllll}
\hline Frequency & \multicolumn{3}{c}{ RICO } & \multicolumn{3}{c}{ DYCOMS } \\
\cline { 2 - 5 } & $\begin{array}{c}\frac{\partial Z}{\partial T} \delta_{T} \\
(\mathrm{dBZ})\end{array}$ & $\frac{\partial Z}{\partial P} \delta_{P}$ & $\frac{\partial Z}{\partial T} \delta_{T}$ & $\frac{\partial Z}{\partial P} \delta_{P}$ \\
& $(\mathrm{dBZ})$ & $(\mathrm{dBZ})$ & $(\mathrm{dBZ})$ \\
\hline $170 \mathrm{GHz}$ & 0.020 & -0.012 & 0.012 & -0.014 \\
$165 \mathrm{GHz}$ & 0.015 & -0.009 & 0.009 & -0.010 \\
$160 \mathrm{GHz}$ & 0.012 & -0.008 & 0.007 & -0.008 \\
$155 \mathrm{GHz}$ & 0.011 & -0.008 & 0.006 & -0.007 \\
$150 \mathrm{GHz}$ & 0.010 & -0.007 & 0.005 & -0.006 \\
$145 \mathrm{GHz}$ & 0.010 & -0.007 & 0.005 & -0.006 \\
$140 \mathrm{GHz}$ & 0.010 & -0.007 & 0.005 & -0.006 \\
\hline
\end{tabular}

Table 4. The fraction of boundary layer range bins detected at $170 \mathrm{GHz}$ and $94 \mathrm{GHz}$ for minimum detectable signals ranging from -40 to $-10 \mathrm{dBZ}$. Also shown is the fraction of range bins containing hydrometers. This analysis is performed after convolution with the assumed antenna gain function.

\begin{tabular}{lrrrr}
\hline & \multicolumn{2}{c}{ RICO } & \multicolumn{2}{c}{ DYCOMS-II RF01 } \\
\cline { 2 - 5 } Hydrometeor & $170 \mathrm{GHz}$ & $94 \mathrm{GHz}$ & $170 \mathrm{GHz}$ & $94 \mathrm{GHz}$ \\
fraction (\%) & 45.2 & 45.2 & 59.2 & 59.2 \\
$-40 \mathrm{dBZ}(\%)$ & 26.6 & 35.9 & 40.0 & 40.0 \\
$-35 \mathrm{dBZ}(\%)$ & 21.9 & 32.1 & 40.0 & 40.0 \\
$-30 \mathrm{dBZ}(\%)$ & 17.2 & 27.7 & 28.1 & 40.0 \\
$-25 \mathrm{dBZ}(\%)$ & 12.6 & 22.6 & 6.2 & 7.4 \\
$-20 \mathrm{dBZ}(\%)$ & 8.4 & 17.5 & 0.0 & 0.0 \\
$-15 \mathrm{dBZ}(\%)$ & 4.7 & 12.7 & 0.0 & 0.0 \\
$-10 \mathrm{dBZ}(\%)$ & 1.9 & 8.3 & 0.0 & 0.0 \\
\hline
\end{tabular}

absorbing $94 \mathrm{GHz}$ channel are shown while the other frequencies lie between these bounds. Assuming infinite radar sensitivity $59.2 \%$ of bins could be sampled in the DYCOMSII RF01 simulation and $45.2 \%$ of the bins could be sampled in the RICO simulation. Obviously, this difference is due to the difference in cloudiness between the two simulations. The sampling of DYCOMS-II RF01 scenario drops precipitously around $-25 \mathrm{dBZ}$ at both frequencies because the thin non-precipitating clouds make for relatively weak scattering targets. We see however that a $-35 \mathrm{dBZ}$ sensitivity radar would permit $40.0 \%$ sampling of the boundary layer bins in DYCOMS-II RF01. Because of the greater diversity of scattering targets in the RICO simulation, there is a more gradual degradation of the sampling as radar sensitivity is reduced. In this case a $-35 \mathrm{dBZ}$ radar would sample $21.9 \%$ of the boundary layer bins and $2 \%$ of bins would still be observable with a $-10 \mathrm{dBZ}$ sensitivity.

\section{Summary}

A differential absorption radar method to remotely sound the water vapor within the cloudy planetary boundary layer is presented. The method requires observations of radar reflectivity at two relatively closely spaced frequencies in the wings of the $183 \mathrm{GHz}$ absorption line. Because the absorption line is strong, frequencies significantly off of the line center, within the line wings and into the continuum absorption region are necessary to penetrate the boundary layer. The DAR method is explored for application to a satellite platform using frequencies spanning the spectral region 140-170 GHz. These frequencies are specific to sampling the cloudy boundary layer from space and are not necessarily ideal for application of DAR to clouds at higher altitudes or different observational platforms.

The feasibility of the DAR method is explored using two high-resolution LES simulations of the cloudy boundary layer coupled to a spectral bin microphysics parameterization. These simulations are meant to capture the natural variability of the atmosphere to the highest fidelity possible so as to realistically assess the potential measurement uncertainties of the approach. The simulations produced are a precipitating cumulus cloud field and a non-precipitating stratocumulus cloud field. These scenarios were chosen because they are the canonical cloud regimes found in regions of transition from high to low boundary layer cloud cover associated with decoupling of boundary layer mixed layers.

Estimation of the total CWV would be possible for all pixels in these simulations using the surface return because the simulated surface reflectivity always exceeds $-5 \mathrm{dBZ}$, which is an achievable radar sensitivity. In the stratocumulus simulation a realistic radar resolution would permit only three pieces of information in the vertical; two atmospheric reflectivities and one surface reflectivity. However the sampling efficiency of the boundary layer would be rather high $(40 \%$ for a $-35 \mathrm{dBZ}$ sensitivity radar) due to the homogenous cloud cover and the shallowness of the boundary layer. In contrast the deeper precipitating clouds in the cumulus simulation would permit sounding through a boundary layer greater than $2 \mathrm{~km}$ depth. However sounding is only possible in cloudy skies and the cumulus simulation has significant amounts of clear sky where only the CWV would be available. In this scenario sampling efficiency is reduced to $29.1 \%$ of boundary layer range bins for a $-35 \mathrm{dBZ}$ radar. Furthermore, in the cumulus simulation the cloudy columns are moister than clear-sky columns, which would introduce a sampling high bias that is not present in the stratocumulus scenario.

Deviation from the expected linear relationship between reflectivity difference and water vapor path is shown to relate to non-uniform beam filling and variation in the spectral dependence of the extinction properties of condensed water. These effects are particularly evident in the presence of precipitation. It is suggested that the channel pair of 160 and $170 \mathrm{GHz}$ maximizes the signal for water vapor while mini- 
mizing noise due to natural variation in the target extinction properties. Assuming an instrument precision of $0.16 \mathrm{dBZ}$ and a retrieval resolution of $500 \mathrm{~m}$, which is similar to CloudSat, retrieval precision would be better than $3 \mathrm{~g} \mathrm{~m}^{-3}$ for the volumetric water vapor content and roughly $1 \mathrm{~kg} \mathrm{~m}^{-2}$ for the CWV. Bias errors in the mean CWV resulting from natural variability are less than $0.25 \mathrm{~kg} \mathrm{~m}^{-2}$. Biases due to uncertainty in the temperature and pressure are negligible. Error due to uncertainty in the spectroscopy, or the radiative propagation model are not explored. Of these potential error sources, uncertainty in the spectroscopy is most likely the largest, and any pursuit of instrument development should be coupled with a dedicated characterization of the spectroscopy.

The analysis presented here is specific to boundary layer clouds. In general, the DAR technique could be applied for water vapor sounding to clouds at all levels. However at higher altitudes the required frequencies would be closer to the line center to maximize signal in a lower vapor environment than would be encountered in the boundary layer. Further studies will focus on generalizing the DAR concept to all clouds.

Acknowledgements. The research described in this paper was carried out at the Jet Propulsion Laboratory, California Institute of Technology, under contract with the National Aeronautics and Space Administration and funded through the internal research and technology development program.

Edited by: S. J. Munchak

\section{References}

Andersson, E., Hólm, E., Bauer, P., Beljaars, A., Kelly, G. A., McNally, A. P., Simmons, A. J., Thépaut, J.-N., and Tompkins, A. M.: Analysis and forecast impact of the main humidity observing systems, Q. J. Roy. Meteor. Soc., 133, 1473-1485, doi:10.1002/qj.112, 2007.

Ao, C. O., Meehan, T. K., Hajj, G. A., Mannucci, A. J., and Beyerle, G.: Lower troposphere refractivity bias in GPS occultation retrievals, J. Geophys. Res.-Atmos., 108, 4577, doi:10.1029/2002JD003216, 2003.

Betts, A. K. and Boers, R.: A Cloudiness Transition in a Marine Boundary Layer, J. Atmos. Sci., 47, 1480-1497, doi:10.1175/1520-0469(1990)047<1480:ACTIAM>2.0.CO;2, 1990.

Bohren, C. F. and Huffman, D. R.: Absorption and scattering of light by small particles, Wiley, New York, 477-482, 1983.

Browell, E. V., Wilkerson, T. D., and McIlrath, T. J.: Water vapor differential absorption lidar development and evaluation, Appl. Optics, 18, 3474, doi:10.1364/AO.18.003474, 1979.

Dee, D. P., Uppala, S. M., Simmons, A. J., Berrisford, P., Poli, P., Kobayashi, S., Andrae, U., Balmaseda, M. A., Balsamo, G., Bauer, P., Bechtold, P., Beljaars, A. C. M., van de Berg, L., Bidlot, J., Bormann, N., Delsol, C., Dragani, R., Fuentes, M., Geer,
A. J., Haimberger, L., Healy, S. B., Hersbach, H., Hólm, E. V., Isaksen, L., Kållberg, P., Köhler, M., Matricardi, M., McNally, A. P., Monge-Sanz, B. M., Morcrette, J.-J., Park, B.-K., Peubey, C., de Rosnay, P., Tavolato, C., Thépaut, J.-N., and Vitart, F.: The ERA-Interim reanalysis: configuration and performance of the data assimilation system, Q. J. Roy. Meteor. Soc., 137, 553-597, doi:10.1002/qj.828, 2011.

Ellis, S. M. and Vivekanandan, J.: Water vapor estimates using simultaneous dual-wavelength radar observations: WATER VAPOR ESTIMATES, Radio Sci., 45, RS5002, doi:10.1029/2009RS004280, 2010.

Eyre, J. R.: The information content of data from satellite sounding systems: A simulation study, Q. J. Roy. Meteor. Soc., 116, 401434, doi:10.1002/qj.49711649209, 1990.

Flower, D. A. and Peckham, G. E.: A Microwave Pressure Sounder, JPL Publication 78-68, Caltech, 1978.

Freilich, M. H. and Vanhoff, B. A.: The Relationship between Winds, Surface Roughness, and Radar Backscatter at Low Incidence Angles from TRMM Precipitation Radar Measurements, J. Atmos. Ocean. Tech., 20, 549-562, doi:10.1175/15200426(2003)20<549:TRBWSR>2.0.CO;2, 2003.

Gordon, C. T., Rosati, A., and Gudgel, R.: Tropical Sensitivity of a Coupled Model to Specified ISCCP Low Clouds, J. Clim., 13, 2239-2260, doi:10.1175/15200442(2000)013<2239:TSOACM>2.0.CO;2, 2000.

Hogan, R. J. and Battaglia, A.: Fast Lidar and Radar MultipleScattering Models. Part II: Wide-Angle Scattering Using the Time-Dependent Two-Stream Approximation, J. Atmos. Sci., 65, 3636-3651, doi:10.1175/2008JAS2643.1, 2008.

Kalmus, P., Wong, S., and Teixeira, J.: The Pacific Subtropical Cloud Transition: A MAGIC Assessment of AIRS and ECMWF Thermodynamic Structure, IEEE Geosci. Remote S., 12, 15861590, doi:10.1109/LGRS.2015.2413771, 2015.

Klein, L. and Swift, C. T.: An improved model for the dielectric constant of sea water at microwave frequencies, IEEE T. Antenn. Propag., 25, 104-111, doi:10.1109/TAP.1977.1141539, 1977.

Kursinski, E. R., Hajj, G. A., Hardy, K. R., Romans, L. J., and Schofield, J. T.: Observing tropospheric water vapor by radio occultation using the Global Positioning System, Geophys. Res. Lett., 22, 2365-2368, doi:10.1029/95GL02127, 1995.

Lawrence, R., Lin, B., Harrah, S., Hu, Y., Hunt, P., and Lipp, C.: Initial flight test results of differential absorption barometric radar for remote sensing of sea surface air pressure, J. Quant. Spectrosc. Ra., 112, 247-253, doi:10.1016/j.jqsrt.2010.06.001, 2011.

Liebe, H. J., Hufford, G. A., and Cotton, M. G.: Propagation modeling of moist air and suspended water/ice particles at frequencies below $1000 \mathrm{GHz}$, in: Proc. AGARD Meeting Atmos. Propag. Effects Through Natural Man-Made Obscurants Visible MM-Wave Radiation, 3/1-3/11, 1993.

Li, L., Heymsfield, G. M., Tian, L., and Racette, P. E.: Measurements of Ocean Surface Backscattering Using an Airborne 94GHz Cloud Radar - Implication for Calibration of Airborne and Spaceborne W-Band Radars, J. Atmos. Ocean. Tech., 22, 10331045, doi:10.1175/JTECH1722.1, 2005.

Lin, B. and Hu, Y.: Numerical simulations of radar surface air pressure measurements at $\mathrm{O}_{2}$ bands, IEEE Geosci. Remote S., 2, 324-328, doi:10.1109/LGRS.2005.848515, 2005.

Ma, C.-C., Mechoso, C. R., Robertson, A. W., and Arakawa, A.: Peruvian Stratus Clouds and the Tropical Pa- 
cific Circulation: A Coupled Ocean-Atmosphere GCM Study, J. Climate, 9, 1635-1645, doi:10.1175/15200442(1996)009<1635:PSCATT>2.0.CO;2, 1996.

Matheou, G. and Chung, D.: Large-Eddy Simulation of Stratified Turbulence. Part II: Application of the Stretched-Vortex Model to the Atmospheric Boundary Layer, J. Atmos. Sci., 71, 44394460, doi:10.1175/JAS-D-13-0306.1, 2014.

Meneghini, R., Liao, L., and Tian, L.: A Feasibility Study for Simultaneous Estimates of Water Vapor and Precipitation Parameters Using a Three-Frequency Radar, J. Appl. Meteorol., 44, 15111525, doi:10.1175/JAM2302.1, 2005.

Millán, L., Lebsock, M., Livesey, N., Tanelli, S., and Stephens, G.: Differential absorption radar techniques: surface pressure, Atmos. Meas. Tech., 7, 3959-3970, doi:10.5194/amt-7-3959-2014, 2014.

Rauber, R. M., Ochs, H. T., Di Girolamo, L., Göke, S., Snodgrass, E., Stevens, B., Knight, C., Jensen, J. B., Lenschow, D. H., Rilling, R. A., Rogers, D. C., Stith, J. L., Albrecht, B. A., Zuidema, P., Blyth, A. M., Fairall, C. W., Brewer, W. A., Tucker, S., Lasher-Trapp, S. G., Mayol-Bracero, O. L., Vali, G., Geerts, B., Anderson, J. R., Baker, B. A., Lawson, R. P., Bandy, A. R., Thornton, D. C., Burnet, E., Brenguier, J.-L., Gomes, L., Brown, P. R. A., Chuang, P., Cotton, W. R., Gerber, H., Heikes, B. G., Hudson, J. G., Kollias, P., Krueger, S. K., Nuijens, L., O’Sullivan, D. W., Siebesma, A. P., and Twohy, C. H.: Rain in Shallow $\mathrm{Cu}-$ mulus Over the Ocean: The RICO Campaign, B. Am. Meteorol. Soc., 88, 1912-1928, doi:10.1175/BAMS-88-12-1912, 2007.

Ray, P. S.: Broadband Complex Refractive Indices of Ice and Water, Appl. Optics, 11, 1836-1844, doi:10.1364/AO.11.001836, 1972.

Rosenkranz, P. W.: Water vapor microwave continuum absorption: A comparison of measurements and models, Radio Sci., 33, 919928, doi:10.1029/98RS01182, 1998.

Salstein, D. A., Ponte, R. M., and Cady-Pereira, K.: Uncertainties in atmospheric surface pressure fields from global analyses, J. Geophys. Res.-Atmos., 113, D14107, doi:10.1029/2007JD009531, 2008.

Stevens, B., Lenschow, D. H., Vali, G., Gerber, H., Bandy, A., Blomquist, B., Brenguier, J.-L., Bretherton, C. S., Burnet, F., Campos, T., Chai, S., Faloona, I., Friesen, D., Haimov, S., Laursen, K., Lilly, D. K., Loehrer, S. M., Malinowski, S. P., Morley, B., Petters, M. D., Rogers, D. C., Russell, L., SavicJovcic, V., Snider, J. R., Straub, D., Szumowski, M. J., Takagi, H., Thornton, D. C., Tschudi, M., Twohy, C., Wetzel, M., and vanZanten, M. C.: Dynamics and Chemistry of Marine Stratocumulus-DYCOMS-II, B. Am. Meteorol. Soc., 84, 579593, doi:10.1175/BAMS-84-5-579, 2003.
Stevens, B., Moeng, C.-H., Ackerman, A. S., Bretherton, C. S., Chlond, A., de Roode, S., Edwards, J., Golaz, J.-C., Jiang, H., Khairoutdinov, M., Kirkpatrick, M. P., Lewellen, D. C., Lock, A., Müller, F., Stevens, D. E., Whelan, E., and Zhu, P.: Evaluation of Large-Eddy Simulations via Observations of Nocturnal Marine Stratocumulus, Mon. Weather Rev., 133, 1443-1462, doi:10.1175/MWR2930.1, 2005.

Suzuki, K., Nakajima, T., Nakajima, T. Y., and Khain, A. P.: A Study of Microphysical Mechanisms for Correlation Patterns between Droplet Radius and Optical Thickness of Warm Clouds with a Spectral Bin Microphysics Cloud Model, J. Atmos. Sci., 67, 1126-1141, doi:10.1175/2009JAS3283.1, 2010.

Takahashi, N., Kimura, T., Ohno, Y., Horie, H., Nakatsuka, H., Sato, K., Sakaide, Y., Okada, K., and Kumagai, H.: Cloud profiling radar on earthcare satellite, in ICCAS-SICE, 2009, 1328-1332, 2009.

Tanelli, S., Durden, S. L., Im, E., Pak, K. S., Reinke, D. G., Partain, P., Haynes, J. M., and Marchand, R. T.: CloudSat's Cloud Profiling Radar After Two Years in Orbit: Performance, Calibration, and Processing, IEEE Trans. Geosci. Remote Sens., 46, 35603573, doi:10.1109/TGRS.2008.2002030, 2008.

Tian, L., Heymsfield, G. M., Li, L., and Srivastava, R. C.: Properties of light stratiform rain derived from $10-$ and $94-\mathrm{GHz}$ airborne Doppler radars measurements, J. Geophys. Res., 112, doi:10.1029/2006JD008144, 2007.

vanZanten, M. C., Stevens, B., Nuijens, L., Siebesma, A. P., Ackerman, A. S., Burnet, F., Cheng, A., Couvreux, F., Jiang, H., Khairoutdinov, M., Kogan, Y., Lewellen, D. C., Mechem, D., Nakamura, K., Noda, A., Shipway, B. J., Slawinska, J., Wang, S., and Wyszogrodzki, A.: Controls on precipitation and cloudiness in simulations of trade-wind cumulus as observed during RICO, J. Adv. Model. Earth Syst., 3, M06001, doi:10.1029/2011MS000056, 2011.

Wentz, F. and T. Meissner: AMSR Ocean Algorithm, Algorithm Theoretical Basis Document, Version 2, Santa Rosa, California, USA, Remote Sensing Systems, 2000.

Zhou, X., Kollias, P., and Lewis, E. R.: Clouds, Precipitation, and Marine Boundary Layer Structure during the MAGIC Field Campaign, J. Climate, 28, 2420-2442, doi:10.1175/JCLI-D-1400320.1, 2015. 